Artigo Revisão

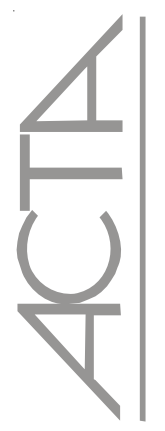

\title{
Pesquisa acadêmica sobre humanização do parto no Brasil: tendências e contribuições
}

\author{
Academic research studies on humanization of childbirth in Brazil: trends and contributions \\ Investigaciones académicas sobre Humanización del Parto en Brasil: tendencias y contribuciones \\ Adriana Lenho de Figueiredo Pereira', Maria Aparecida \\ Vasconcelos Moura ${ }^{2}$, Ivis Emília de Olveira Souza ${ }^{3}$, Maria \\ Antonieta Rubio Tyrrel ${ }^{4}$, Marléa Chagas Moreira ${ }^{5}$
}

\section{RESUMO}

Objetivos: Realizamos um levantamento das pesquisas acadêmicas brasileiras dos programas de pós-graduação stricto sensu acerca da humanização do parto e nascimento, de forma a identificar a distribuição temporal, regional, por abordagem metodológica e área de conhecimento, e analisar as contribuições desta produção acadêmica para a prática assistencial. Métodos: Pesquisa exploratória e descritiva. Os dados foram coletados através dos resumos de teses e dissertações disponíveis em bases de dados de bibliotecas virtuais, BIREME e CAPES. Resultados: Foram encontradas 26 dissertações e 4 teses no período de 1987 a 2004. A maioria (20; 66,7\%) foi desenvolvida em programas de pós-graduação da região Sudeste. Mais da metade (16;53,3\%) do total foi realizada em programas de pós-graduação de enfermagem. A metodologia qualitativa foi a mais utilizada (25; 80\%). Os aspectos ético-políticos da assistência predominaram $(20 ; 66,7 \%)$ sobre os aspectos técnicos nas sínteses dos resultados e conclusões das pesquisas estudadas. Conclusão: As pesquisas de pós-graduação propõem mudança de paradigma técnico-científico, na formação profissional, na atitude profissional frente aos direitos humanos e sociais, e uma redefinição de papeis profissionais das enfermeiras e parteiras.

Descritores: Saúde da mulher; Parto humanizado; Dissertações acadêmicas; Pesquisas em enfermagem

\begin{abstract}
Objectives: To conduct a survey among Brazilian academic research studies on humanization of childbirth, to identify timing, location, topic, and methodological approaches, and to determine whether or not these academic research studies contributed to nursing practice. Methods: This was an exploratory descriptive study. Abstracts of doctoral dissertations and master's theses were retrieved from two databases: Virtual Health Library (BIREME - OPAS/OMS) and Coordination for the Improvement of Higher Education Personnel (CAPES) of the Brazilian Ministry of Education. Results: 26 dissertations and 4 theses were found in the period of 1987 the 2004 . The majority $(20 ; 66.7 \%)$ of these academic research studies were conducted on graduate programs of Southeast Brazil. More than a half of theses studies $(16 ; 53.3 \%)$ were conducted in graduate programs in nursing. The majority of the studies $(24 ; 80 \%)$ used qualitative methodology. Ethical-political aspects of health care were the most common topics or themes (20; 66.7\%). Conclusion: Graduate research studies propose technician-scientific paradigm change, professional education, professional attitude towards the social and human rights, and redefinition of professional roles of nurses and midwives.
\end{abstract}

keywords: Woman's health; Humanizing delivery; Dissertations, academic; Nursing research

\section{RESUMEN}

Objetivos: Fue realizado un levantamiento de las investigaciones académicas brasileñas de los programas de postgrado stricto sensu respecto a la humanización del parto y nacimiento, de forma a identificar la distribución temporal, regional, por abordaje metodológico y área del conocimiento, y analizar las contribuciones de esta producción académica para la práctica asistencial. Métodos: Se trata de uma investigación exploratória y descriptiva. Los datos fueron recolectados a través de los resúmenes de tesis de maestría y de doctorado disponibles en las bases de datos de bibliotecas virtuales, BIREME y CAPES. Resultados: Fueron encontradas 26 tesis de maestría y 4 tesis de doctorado en el período de 1987 al 2004. La mayoría (20; 66,7\%) fue desarrollada en programas de postgrado de la región sudeste. Más de la mitad (16; $53,3 \%)$ del total fue realizada en programas de postgrado de enfermería. La metodología cualitativa fue la más utilizada (25; $80 \%)$. Los aspectos ético-políticos de la asistencia predominaron (20;66,7\%) sobre los aspectos técnicos en las síntesis de los resultados y conclusiones de las investigaciones estudiadas. Conclusión: Las investigaciones de postgrado proponen cambios de paradigma técnico-científico, en la formación profesional, en la actitud profesional frente a los derechos humanos y sociales, y una redefinición de los papeles profesionales de las enfermeras y parteras.

Descriptores: Salud de la mujer; Parto humanizado; Tesis académicas; Investigaciones en enfermería

\footnotetext{
Pós-graduanda da Escola de Enfermagem Anna Nery da Universidade Federal do Rio de Janeiro - UFRJ - Rio de Janeiro (RJ), Brasil; Professora Assistente do Departamento de Enfermagem Materno-Infantil da Faculdade de Enfermagem da Universidade Estadual do Rio de Janeiro - UERJ - Rio de Janeiro (RJ), Brasil.

2 Professora Adjunto da Escola de Enfermagem Anna Nery da Universidade Federal do Rio de Janeiro - UFRJ - Rio de Janeiro (RJ), Brasil.

${ }^{3}$ Professora Titular da Escola de Enfermagem Anna Nery da Universidade Federal do Rio de Janeiro - UFRJ - Rio de Janeiro (RJ), Brasil.

${ }^{4}$ Professora Titular; Diretora da Escola de Enfermagem Anna Nery da Universidade Federal do Rio de Janeiro - UFRJ - Rio de Janeiro (RJ), Brasil.

${ }_{5}^{5}$ Professora Adjunto da Escola de Enfermagem Anna Nery da Universidade Federal do Rio de Janeiro - UFRJ - Rio de Janeiro (RJ), Brasil.
} 


\section{INTRODUÇÃO}

A temática da humanização do parto e nascimento tem feito parte da agenda de discussões em fóruns científicos, sociais e das políticas públicas de saúde nas últimas décadas. A partir da mobilização social dos segmentos feministas em defesa dos direitos sexuais e reprodutivos da mulher ${ }^{(1)}$ e de um conjunto eclético de profissionais críticos e discordantes do modelo assistencial medicalizado dominante no país ${ }^{(2-3)}$, o Ministério da Saúde estabelece políticas e programas voltados para a Humanização do Parto e Nascimento a partir de $2000^{(4-5)}$.

O termo humanização pode agregar diferentes significados. Busca expressar uma mudança na compreensão do parto como experiência humana, gerando interpretações de diversas influências no campo ideológico-cultural. Os principais sentidos atribuídos ao termo podem ser agrupados em sentidos relacionados aos aspectos de ordem técnica e de ordem ético-política. O primeiro agrupamento refere-se aos sentidos de humanização relacionados com a assistência baseada em evidências científicas, que utilizam a tecnologia apropriada e inspirado no paradigma da desmedicalização da atenção ao parto e nascimento. $O$ parto passa a ser compreendido como um evento "natural" e fisiológico, resgatando-se a competência instintiva feminina no processo parturitivo ${ }^{(3-4)}$.

Nos sentidos identificados com aspectos éticospolíticos, a humanização foi associada com uma assistência baseada principalmente nos direitos humanos das mulheres, assim como dos bebês e da família. Reivindica práticas que promovam a autonomia, a liberdade de escolha, a eqüidade, a não-violência de gênero e as demais violações de direitos nos serviços de saúde.

Nesse conjunto de sentidos há busca pela democratização das relações de poder entre os sujeitos no campo da saúde. Primeiro, na relação cliente-profissional através da promoção do acolhimento e do cuidado integral e sensível às necessidades psíquicas, culturais e sociais, por meio de um processo dialógico nas ações de cuidado. Segundo, nas relações entre os profissionais de saúde, redimensionando os papéis e poderes no cenário do parto e nascimento possibilitando a atuação da enfermeira obstetra no parto normal, deslocando a função quase exclusiva do cirurgião obstetra na assistência. Por outro lado, o centro cirúrgico deixa de ser o local privilegiado do parto, restituindo a importância da sala de parto e concebendo novos cenários de atendimento, os centros de parto normal e as casas de parto(3).

A discussão sobre humanização do parto e nascimento vem aglutinando debates e críticas ao modelo assistencial dominante - hierarquizado, fragmentado e calcado na lógica técnico-burocrática. Propõe ações voltadas para processos de subjetivação transformadores, ou seja, envolve sujeitos coletivos que nas práticas concretas e cotidianas transformam o modo de produzir cuidados em saúde, transformando-se a si também ${ }^{(6)}$. Dessa forma, este movimento social busca a transformação no modo de pensar e de fazer no campo das práticas assistenciais.

Esses processos de subjetivação situam-se na esfera das interações, das relações face-a-face que se constroem no cotidiano, que são denominadas de "assistência"((). Neste sentido, a formação profissional é crucial para a disseminação de mecanismos ideológicos contrahegemônicos e de alianças que garantam adesão e continuidade desse processo de transformação.

No âmbito do conhecimento científico e da formação profissional, a academia é um microcosmo social de produção, reprodução e transformação dos modos de pensar e de fazer, que tem no seu interior o movimento dialético entre ortodoxia e a heterodoxia. A pesquisa acadêmica reflete esse movimento dialético na produção de conhecimentos. Sob esta perspectiva, procurou-se investigar como a humanização do parto e nascimento tem se refletido nas produções acadêmicas de mestrado e doutorado no país e como seus principais resultados podem contribuir para a prática assistencial.

Este estudo objetivou realizar um levantamento das dissertações e teses brasileiras acerca da humanização do parto e nascimento; identificar a distribuição temporal, regional, por abordagem metodológica e por área de conhecimento destas pesquisas e analisar as contribuições desta produção acadêmica para a prática assistencial, a partir da síntese dos resultados e da conclusão contidos nos resumos desses estudos.

\section{MÉTOdOS}

Sob uma abordagem quantitativa, empreendemos uma pesquisa documental de caráter exploratório e descritivo. Utilizamos como fonte de dados os resumos de teses e dissertações disponíveis em duas bases de dados de bibliotecas virtuais, no mês de junho de 2005. A primeira é o Banco de Teses do Portal CAPES Coordenação de Aperfeiçoamento de Pessoal de Nível Superior - órgão do Ministério da Educação responsável pela política nacional de pós-graduação stricto sensu em todos Estados da federação. A segunda é a Biblioteca Virtual em Saúde (BVS) do Centro Latinoamericano e do caribe de Informação em Ciências da Saúde (BIREME), da Organização Pan-Americana de Saúde e da Organização Mundial de Saúde. Nesta biblioteca, utilizamos a base de dados LILACS - Literatura LatinoAmericana e do Caribe em Ciências da Saúde.

A escolha dessas duas bases de dados deveu-se à representatividade e abrangência nacional de ambas: a BIREME por disponibilizar pesquisas científicas de todas as áreas do conhecimento que investigam sobre a saúde humana; a CAPES como órgão regulador de todos os 
programas de mestrado e doutorado reconhecidos no país. A CAPES determina que as pesquisas efetuadas nestes programas sejam registradas nesta coordenação sendo as mesmas incorporadas ao respectivo banco de dados.

Esclarecemos que, no período de coleta de dados, a base de dados BIREME disponibilizava teses e dissertações produzidas até 2004 e o Portal Capes, trabalhos de até 2003.

Utilizamos como critério de seleção dos resumos das teses e dissertações a busca pelas palavras combinadas: partohumanizado; humanização-parto; nascimento-humanizado e humanização-nascimento. Estas palavras deveriam aparecer no título e/ou no texto do resumo dos estudos. Os dados receberam unicamente tratamento estatístico descritivo, devido a quantidade reduzida de trabalhos encontrados. Os dados são apresentados através de figura e tabela descritos pelas suas freqüências absolutas e relativas.

Para analisar as contribuições para a prática assistencial das teses e dissertações selecionadas, as sínteses dos resultados e conclusões nos resumos foram agrupadas de acordo com a similaridade temática dos achados e, posteriormente, estes foram classificados de acordo com o sentido de humanização, de ordem técnica e de ordem ético-política, expresso nessas sínteses.

\section{RESULTADOS}

Encontramos um total de 30 resumos nas bases de dados pesquisadas (Anexo 1). Dentre estes, 26 (86,7 \%) corresponderam a resumos de dissertações de mestrado e $4(13,3 \%)$, a resumos de teses de doutorado. Quanto ao ano de defesa das produções científicas, a maioria (26; $86,7 \%$ ) foi a partir de 2000 , e os demais nas duas décadas anteriores. Foram defendidas $3(10 \%)$ na década de noventa e $1(3,3 \%)$ na década de oitenta. O único trabalho da década de 80 é uma dissertação de enfermagem, defendida em 1987. Na década de 90, os trabalhos encontrados datam de 1997 em diante.

Quanto à distribuição regional, a grande maioria (20; $66,7 \%$ ) das dissertações e teses foram produzidas em programas de pós-graduação da região Sudeste. Ressaltamos que foram encontrados trabalhos produzidos em outros Estados da federação, como Santa Catarina, Rio Grande do Sul, Ceará, Bahia, Rio Grande do Norte e Distrito Federal.

Em relação à distribuição por área de conhecimento dos programas de pós-graduação stricto sensu, identificamos que a temática tem despertado interesse de um conjunto variado de disciplinas, como a Enfermagem, Saúde Pública e Coletiva, Arquitetura, Medicina, Psicologia, Educação e Multidisciplinar. No entanto, mais da metade (16; 53,3\%) dos trabalhos foram produzidos pelos programas de pós-graduação em Enfermagem. Esclarecemos que a área de conhecimento classificada como multidisciplinar corresponde ao Programa de Pós-
Graduação em Ciências da Saúde da Universidade de Brasília e em Saúde da Mulher e da Criança do Instituto Fernandes Figueiras da Fundação Oswaldo Cruz.

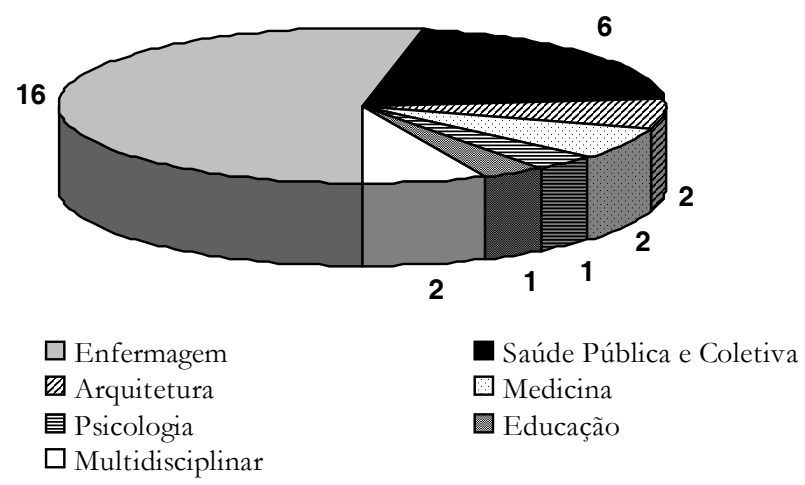

Figura 1 - Distribuição das dissertações e teses sobre a Humanização do parto e nascimento por área do conhecimento dos programas de pós-graduação stricto sensu. Brasil, 1980-2004.

A abordagem qualitativa foi preponderante nas pesquisas de pós-graduação, representando $80 \%$ (30) dos estudos encontrados. Nestas pesquisas, algumas utilizaram métodos compreensivos como representações sociais, história de vida, interacionismo simbólico, fenomenologia, entre outros ( Anexo 1).

Os aspectos ético-políticos predominaram (20; 66,7\%) sobre os aspectos técnicos nos resultados e conclusões das teses e dissertações estudadas. Mais da metade dos estudos consideraram ser necessária a mudança de atitude profissional frente aos direitos humanos e sociais e a democratização na relação de poder entre o profissional e o cliente, correspondendo, respectivamente, a 33,3 \% (10) e 23,4 \% (7). Tal distribuição pode ser observada na Tabela 1.

Tabela 1 - Distribuição das dissertações e teses sobre humanização do parto e nascimento, segundo a síntese dos resultados e conclusão das pesquisas. Brasil, 1980-2004.

\begin{tabular}{lrr}
\hline \multicolumn{1}{c}{$\begin{array}{c}\text { Síntese dos resultados e conclusão das } \\
\text { pesquisas }\end{array}$} & $\mathbf{N}$ & $\mathbf{\%}$ \\
\hline Ordem técnica & 10 & 33,3 \\
\hline $\begin{array}{l}\text { Estratégias de formação profissional para } \\
\text { aquisição de conhecimento sobre } \\
\text { humanização }\end{array}$ & 4 & 13,3 \\
$\begin{array}{l}\text { Mudança de paradigma técnico-científico } \\
\text { Modificação na concepção do espaço } \\
\text { assistencial }\end{array}$ & 4 & 13,3 \\
\hline Ordem ético-política & 2 & 6,7 \\
\hline $\begin{array}{l}\text { Democratização na relação de poder entre o } \\
\text { profissional e o cliente }\end{array}$ & 20 & 66,7 \\
$\begin{array}{l}\text { Mudança de atitude profissional frente aos } \\
\text { direitos humanos e sociais }\end{array}$ & 7 & 23,4 \\
$\begin{array}{l}\text { Redefinição de papeis profissionais das } \\
\text { enfermeiras e parteiras }\end{array}$ & 3 & 33,3 \\
\hline
\end{tabular}




\section{DISCUSSÃO}

Com a implantação de políticas e programas ministeriais para a melhoria da qualidade e humanização do parto e nascimento ${ }^{(2-5)}$, houve expressivo aumento no quantitativo de pesquisas stricto sensu sobre o tema a partir de 2000. A participação majoritária das pesquisas de programas de mestrado e doutorado em enfermagem pode sinalizar que a temática tem assumido particular interesse por esta disciplina, resultante do estímulo à atuação e à formação de enfermeiras obstétricas, a partir da implantação destas políticas e programas ${ }^{(2-7)}$.

O percurso metodológico qualitativo foi o mais utilizado pelas pesquisas. Os aspectos relacionados à subjetividade e intersubjetividade humana constituem o campo de investigação qualitativa ${ }^{(8)}$. As propostas de humanização buscam a valorização da subjetividade, da afetividade, do prazer e da liberdade.

As pesquisas de pós-graduação stricto sensu sobre humanização do parto e nascimento contribuem para uma reflexão crítica da prática assistencial, na perspectiva dos paradigmas técnico-científicos, das relações de poder e de gênero. No paradigma técnico-científico hegemônico o controle da natureza inclui o controle do $\operatorname{corpo}^{(9)}$. A proposição feminista de autonomia do corpo feminino é contraposta nas vivências das mulheres no cotidiano dos serviços de saúde, em conseqüência das práticas e representações associadas à medicalização do corpo feminino ${ }^{(4)}$. Nas teses e dissertações há discussão de questões relacionadas aos direitos humanos e sociais, à democratização das relações interpessoais e interprofissionais em saúde.

A proposta de assistência humanizada contribui para o questionamento de aspectos relacionados à vida humana e busca uma reconfiguração da técnica e do espaço de cuidado ao parto e nascimento. Como estratégia para esta reconfiguração, as pesquisas da pós-graduação stricto sensu apontaram a importância da formação profissional em saúde, voltada para o resgate do respeito à vida humana, considerando-se os aspectos sociais, culturais, éticos e emocionais da clientela. A humanização surge como uma proposta de redefinição das relações humanas na assistência, como revisão do projeto de cuidado, e mesmo da compreensão da condição humana e de direitos humanos ${ }^{(3)}$.

\section{CONCLUSÃO}

As pesquisas brasileiras de pós-graduação stricto sensu sobre humanização do parto e nascimento contribuem para a reflexão e a crítica da prática assistencial decorrente do modelo tecnocrático, curativo e especializado. Propõem mudanças de ordem técnica, no paradigma técnico-científico em saúde e na formação profissional, e de ordem ético-política, na atitude profissional frente aos direitos humanos e sociais, na relação de poder entre o profissional e o cliente, e na redefinição de papeis profissionais das enfermeiras e parteiras.

Essas pesquisas expressam uma mudança na concepção de saúde, de gênero, de cuidado à saúde, de processo de trabalho em saúde, representando o movimento dialético entre a sociedade acadêmica e a sociedade civil no campo da saúde da mulher.

\section{REFERÊNCIAS}

1. Ávila MB. Direitos sexuais e reprodutivos: desafios para as políticas de saúde. Cad Saúde Pública = Rep Public Health. 2003, 19 (Supl 2): 465- 9.

2. SchirmerJ. Assistência ao parto: novas diretrizes governamentais. Acta Paul Enfermagem. 2000; 13 (N Esp Pt 1): 214-21.

3. Deslandes SF. A ótica de gestores sobre a humanização da assistência nas maternidades municipais do Rio de Janeiro. Ciênc Saúde Coletiva. 2005; 10(3): 615-26.

4. Diniz CSG. Humanização da assistência ao parto no Brasil: os muitos sentidos de um movimento. Ciênc Saúde Coletiva. 2005; 10(3): 627-37.

5. Serruya SJ, Lago TDG, CecattiJG. O panorama da atenção prénatal no Brasil e o Programa de Humanização do Pré-natal e Nascimento. Rev Bras Saúde Matern Infant. 2004; 4(3): 269-79.

6. Deslandes SF. O projeto ético-político da humanização: conceitos, métodos e identidade. Interface Comun Saúde Educ. 2005; 9(17): 389-406.

7. Riesco MLG, Fonseca RMGS. Elementos constitutivos da formação e inserção de profissionais não-médicos na assistência ao parto. Cad Saúde Pública = Rep Public Health. 2002; 18(3): 685-98.

8. Turato ER. Métodos qualitativos e quantitativos na área de saúde: definições, diferenças e seus objetos de pesquisa. Rev Saúde Pública = J Public Health. 2005; 39(3): 507-14.

9. Davis-Floyd RE. The technocratic body: American childbirth as cultural expression. Soc Sci Med.1994; 38(8): 1125-40. 


\begin{tabular}{|c|c|c|c|c|}
\hline 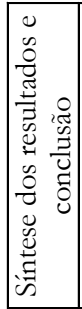 & 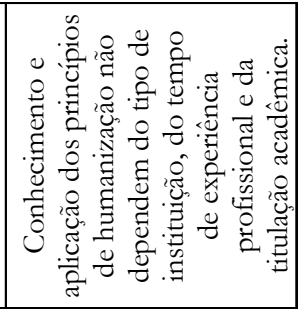 & 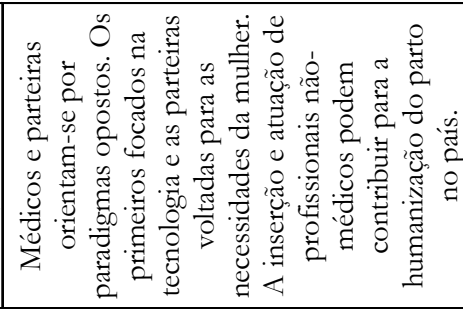 & 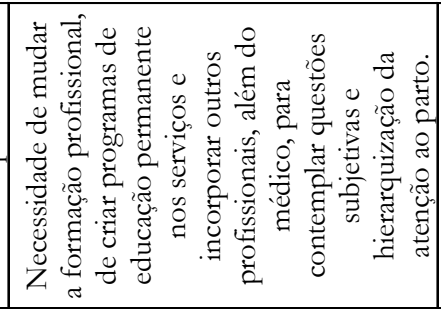 & 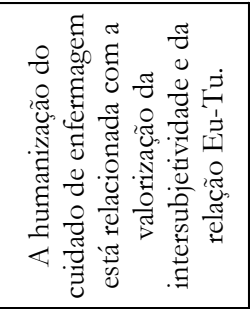 \\
\hline 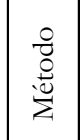 & & 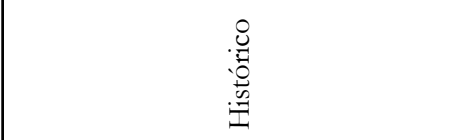 & & \\
\hline 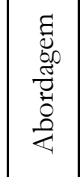 & 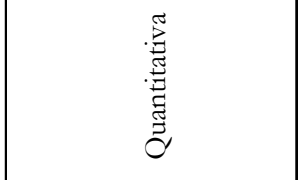 & 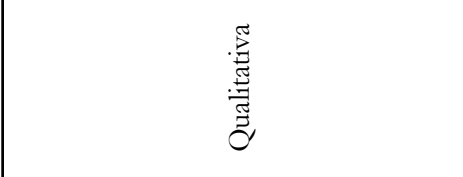 & 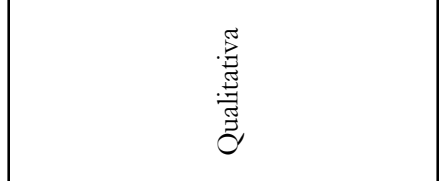 & 㺃 \\
\hline 㑒 & $\begin{array}{l}\infty \\
\stackrel{\infty}{\sigma}\end{array}$ & ڤે & $\hat{\sigma}$ & $\stackrel{\infty}{\stackrel{\circ}{\sigma}}$ \\
\hline 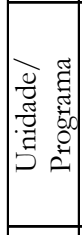 & 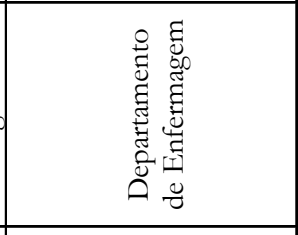 & 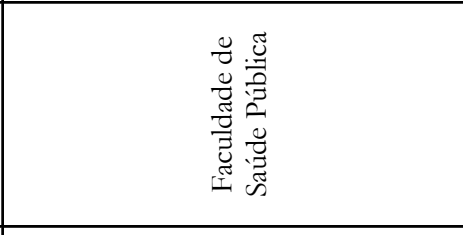 & 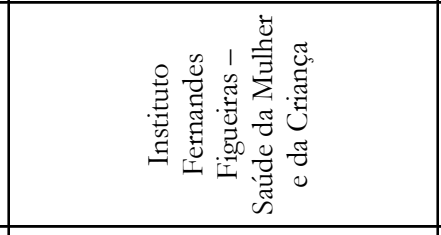 & 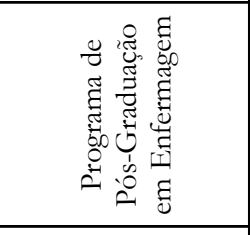 \\
\hline 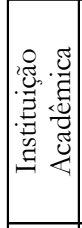 & 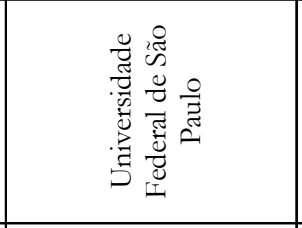 & 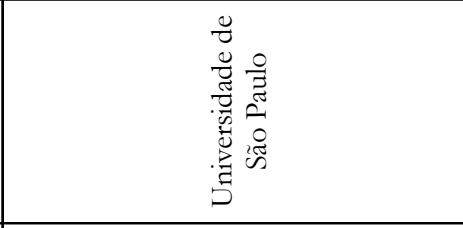 & 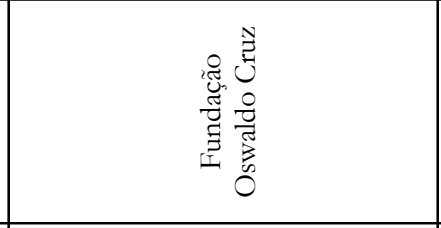 & 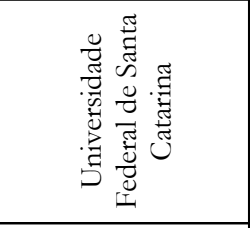 \\
\hline 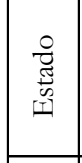 & 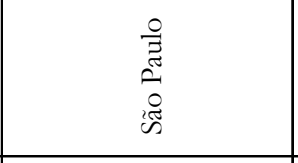 & 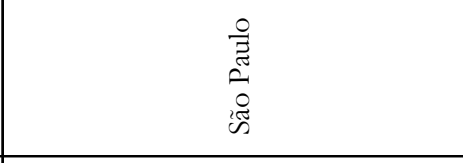 & 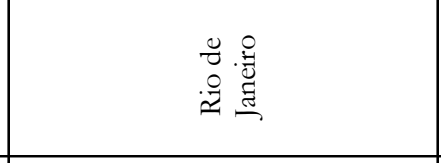 & 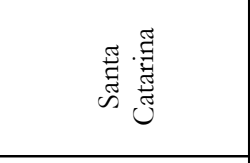 \\
\hline 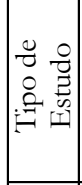 & 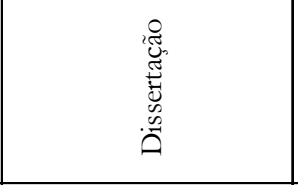 & 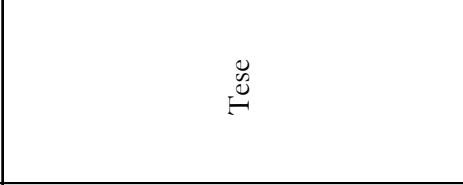 & 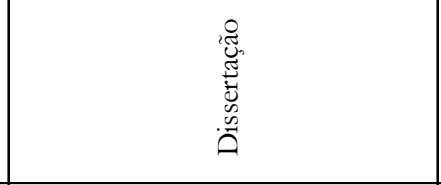 & 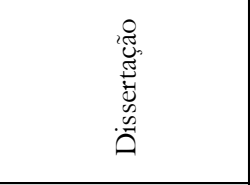 \\
\hline$\stackrel{\circ}{\stackrel{B}{E}}$ & 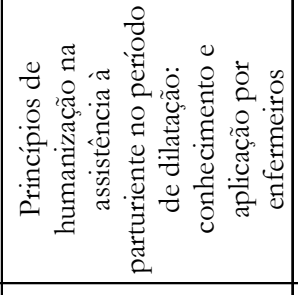 & 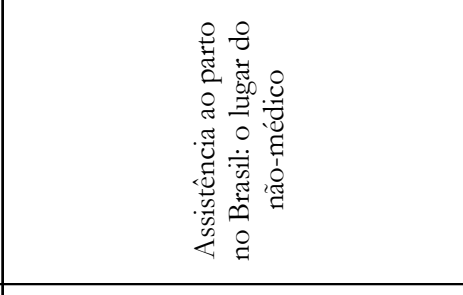 & 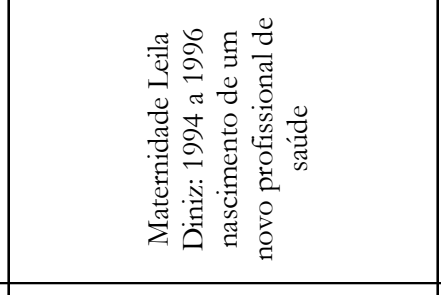 & 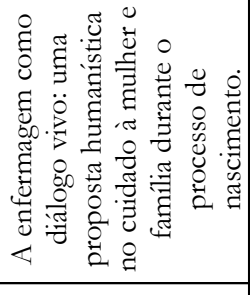 \\
\hline 苞 & 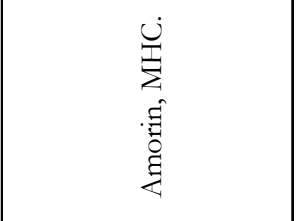 & 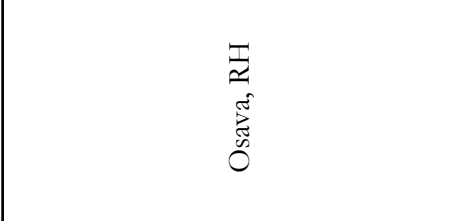 & 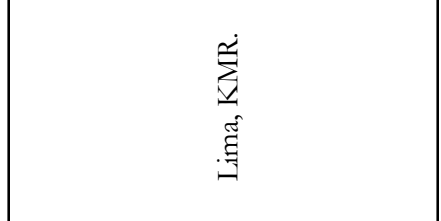 & 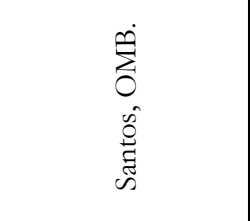 \\
\hline Z & - & $\sim$ & $n$ & + \\
\hline
\end{tabular}




\begin{tabular}{|c|c|c|c|}
\hline 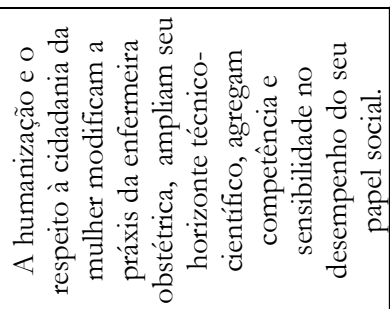 & 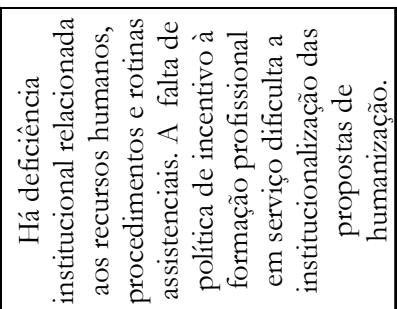 & 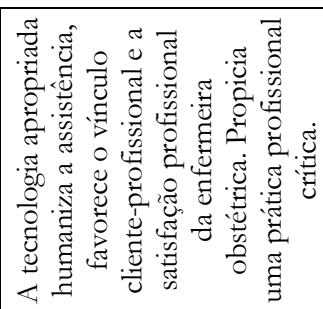 & 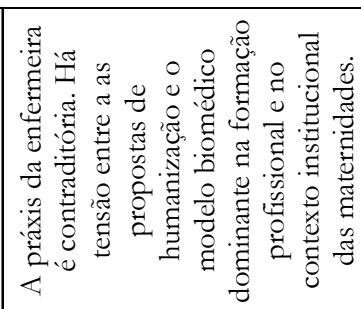 \\
\hline 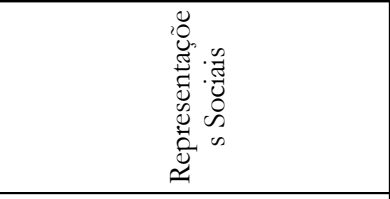 & & & 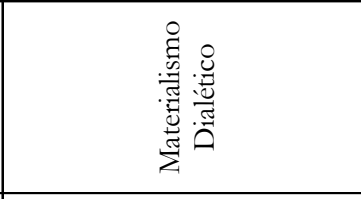 \\
\hline 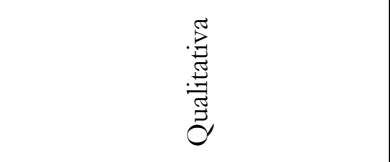 & 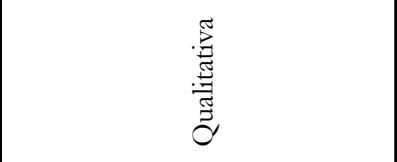 & 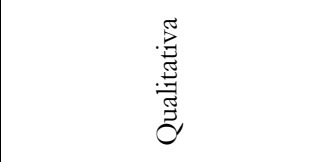 & 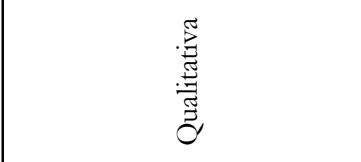 \\
\hline ¿্ণ & 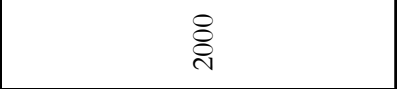 & 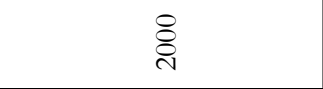 & $\overline{\mathrm{\sigma}}$ \\
\hline 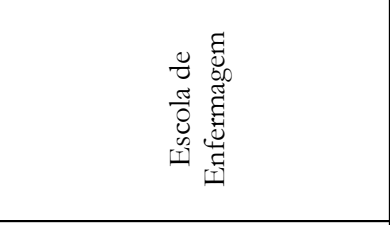 & 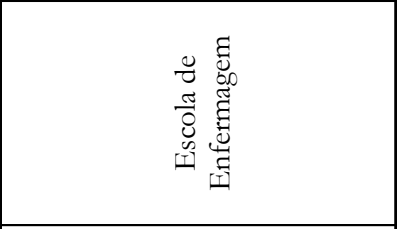 & 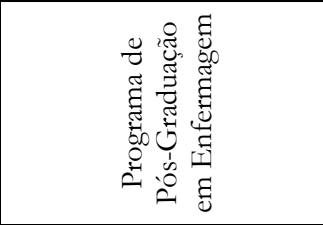 & 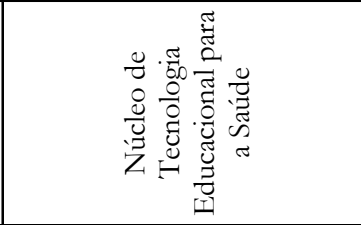 \\
\hline 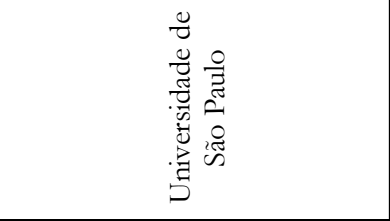 & 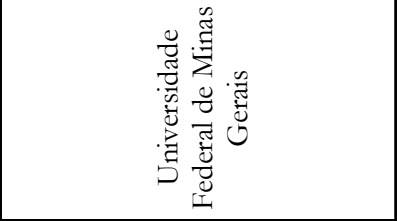 & 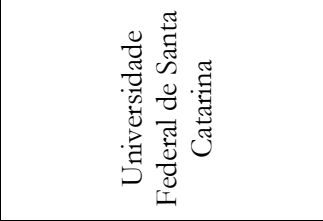 & 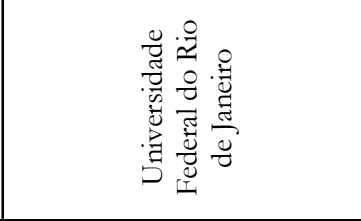 \\
\hline 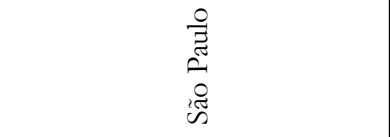 & 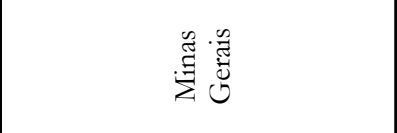 & 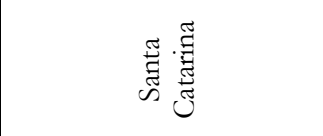 & 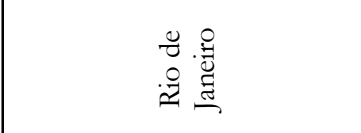 \\
\hline $\begin{array}{l}\stackrel{\mathscr{O}}{6} \\
\end{array}$ & 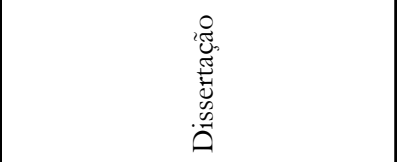 & 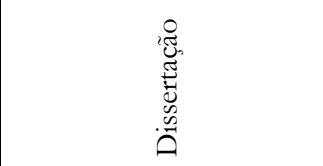 & 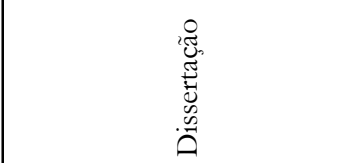 \\
\hline 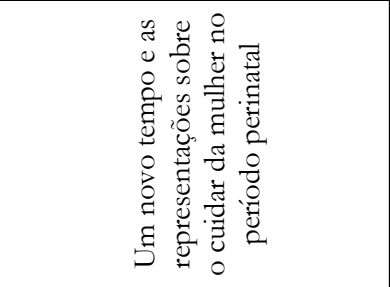 & 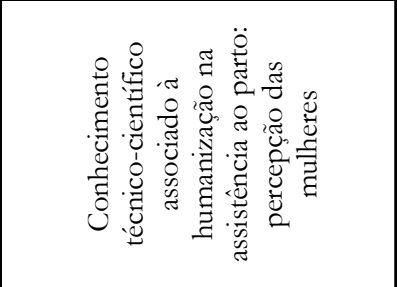 & 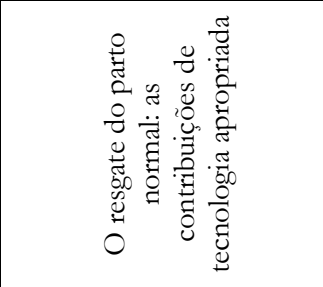 & 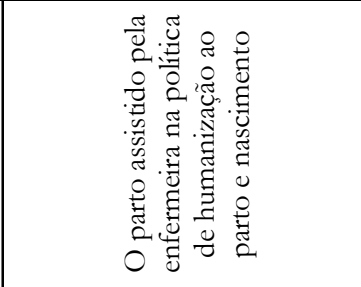 \\
\hline 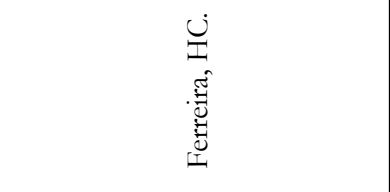 & 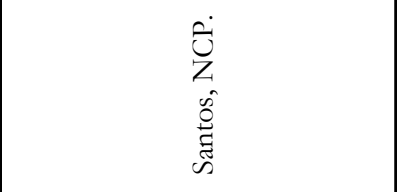 & 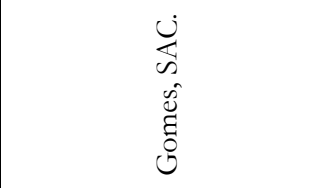 & 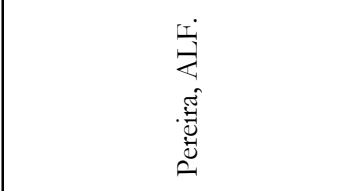 \\
\hline in & 0 & $r$ & $\infty$ \\
\hline
\end{tabular}




\begin{tabular}{|c|c|c|c|}
\hline 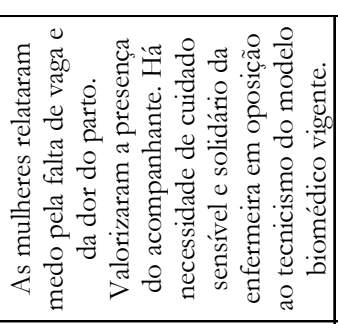 & 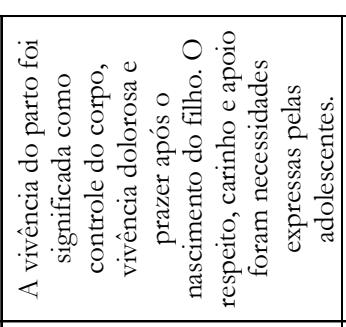 & 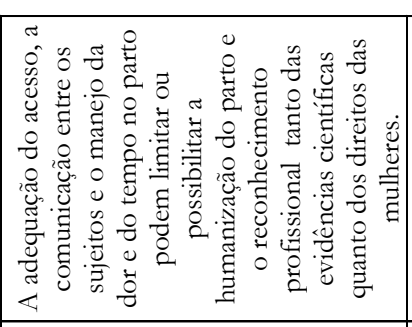 & 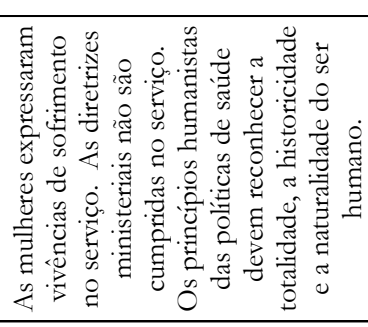 \\
\hline & 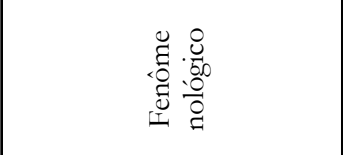 & 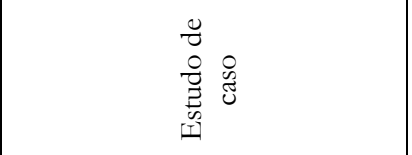 & \\
\hline : & 莺 & 莺 & 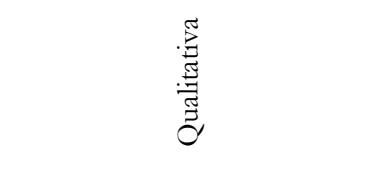 \\
\hline ఠ్రి & 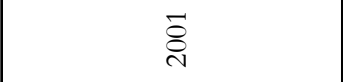 & $\overline{\stackrel{ఠ}{~}}$ & 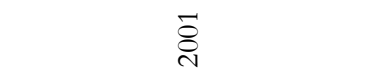 \\
\hline 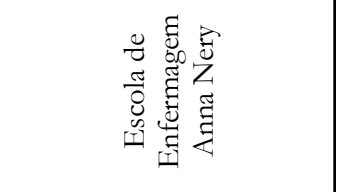 & 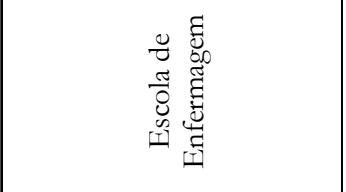 & 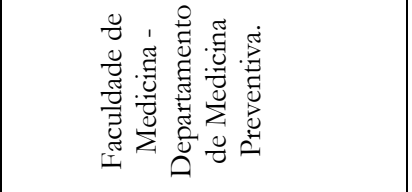 & 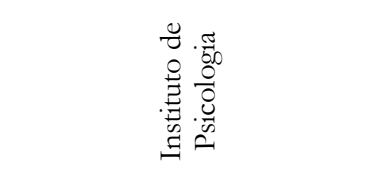 \\
\hline 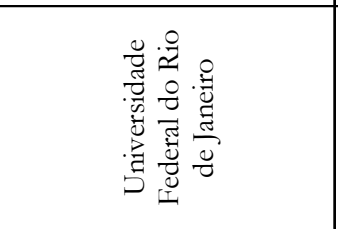 & 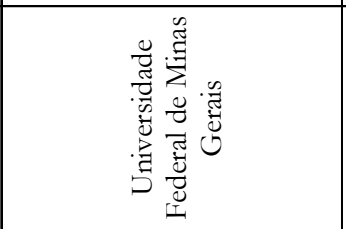 & 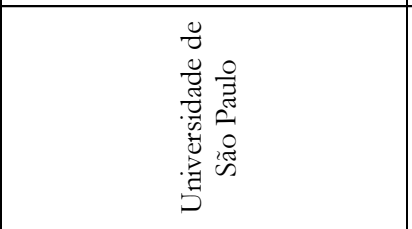 & 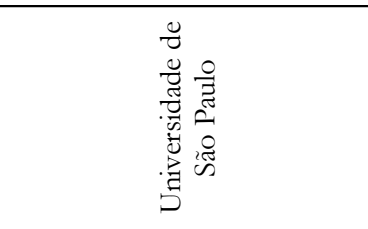 \\
\hline 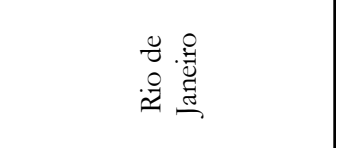 & 卷 & 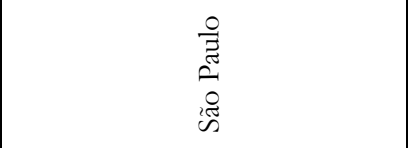 & 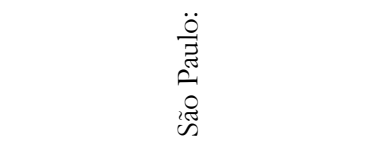 \\
\hline 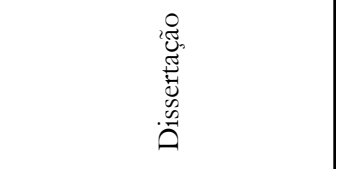 & 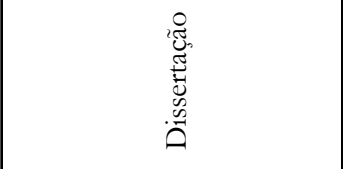 & $\begin{array}{c}\stackrel{\mathscr{B}}{\leftrightarrow} \\
\stackrel{\leftrightarrow}{H}\end{array}$ & 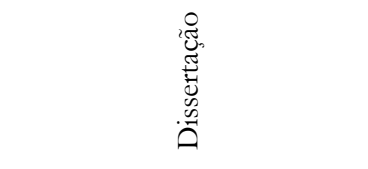 \\
\hline 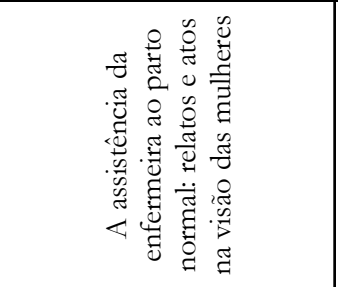 & 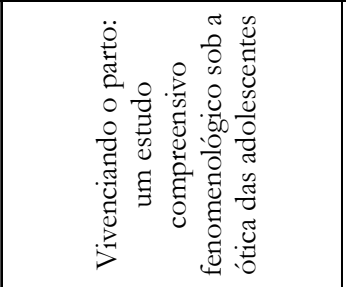 & 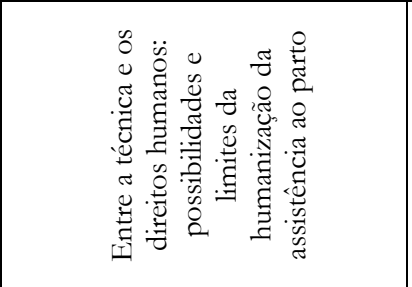 & 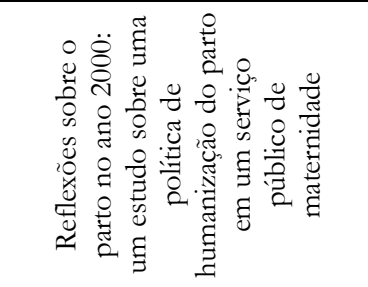 \\
\hline 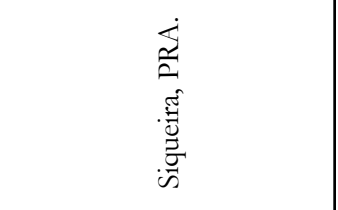 & 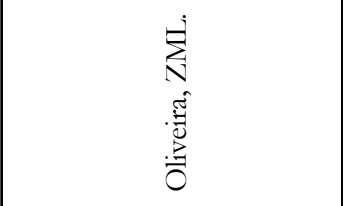 & $\begin{array}{l}\dot{U} \\
\dot{U} \\
\hat{\Xi} \\
\hat{D}\end{array}$ & 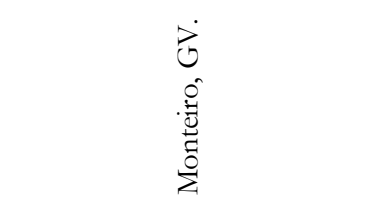 \\
\hline$a$ & $\stackrel{\rho}{\circ}$ & $\exists$ & $\cong$ \\
\hline
\end{tabular}




\begin{tabular}{|c|c|c|c|c|}
\hline 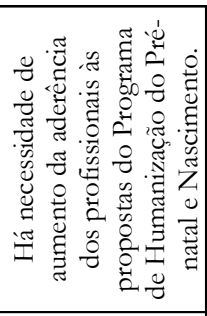 & 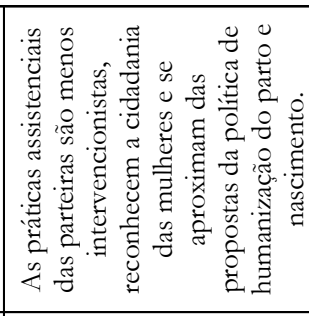 & 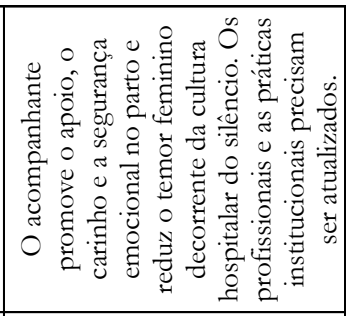 & 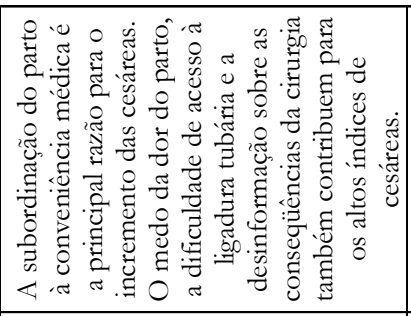 & 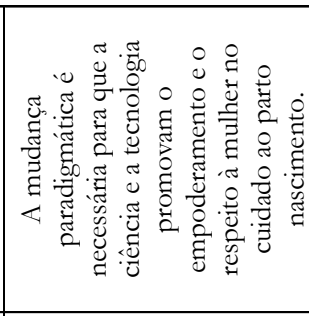 \\
\hline 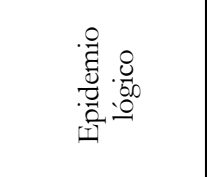 & 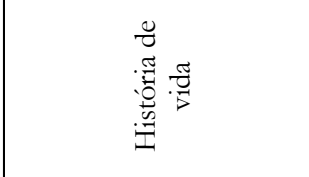 & 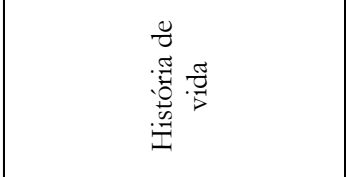 & & 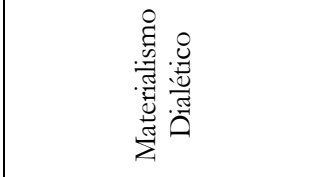 \\
\hline 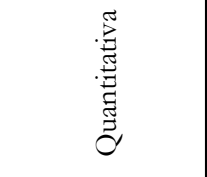 & 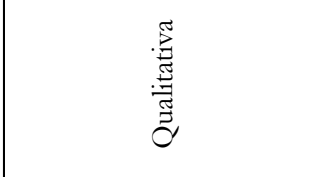 & 莺 & 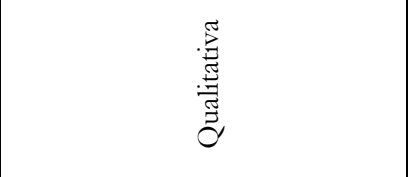 & 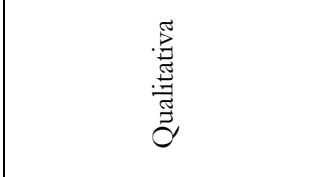 \\
\hline ठิ & \&్ & 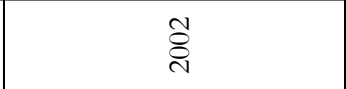 & §̊) & \&్ \\
\hline 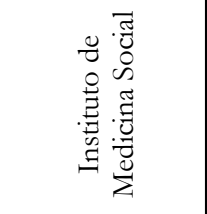 & 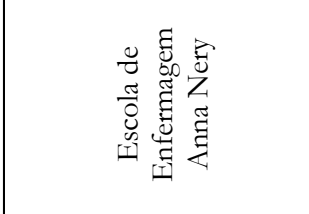 & 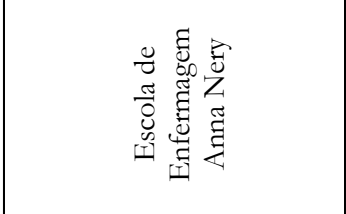 & 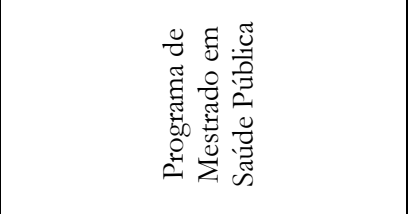 & 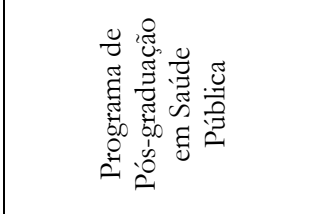 \\
\hline 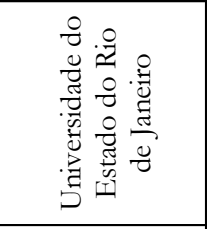 & 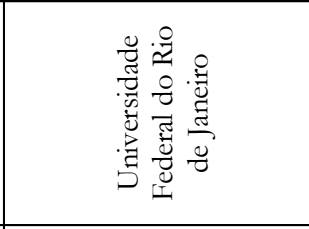 & 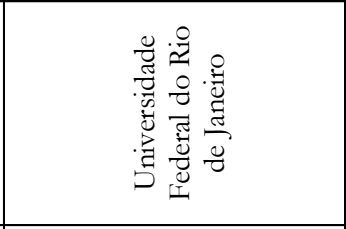 & 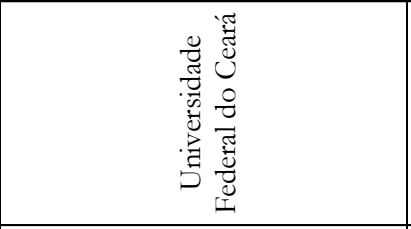 & 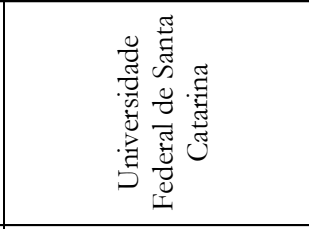 \\
\hline 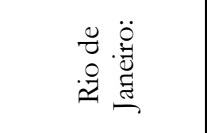 & 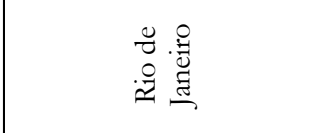 & 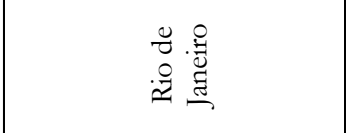 & Uूँّ & 茎 \\
\hline 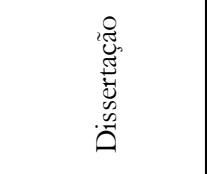 & 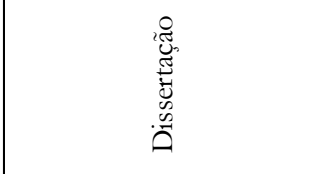 & 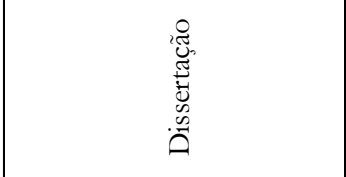 & 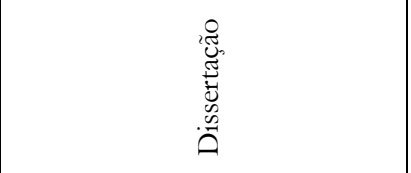 & 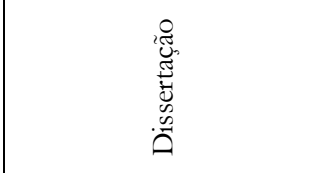 \\
\hline 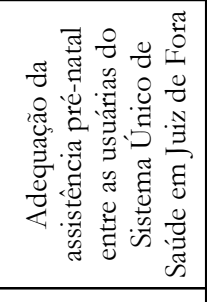 & 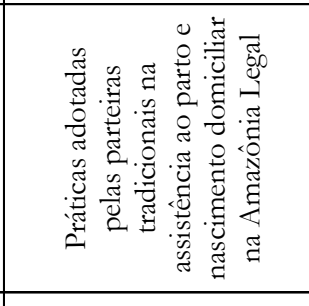 & 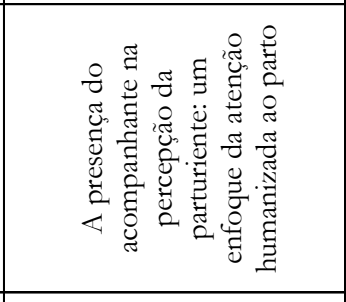 & 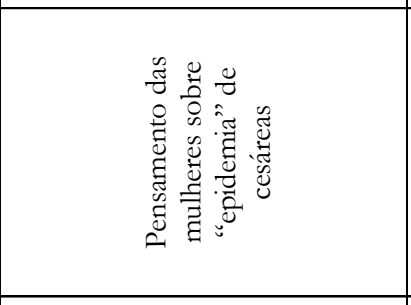 & 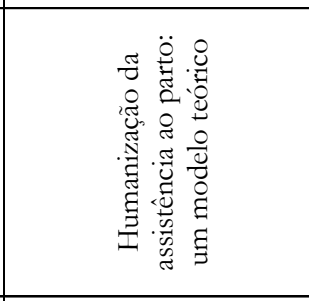 \\
\hline 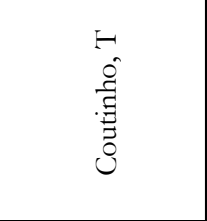 & 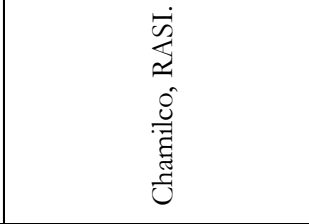 & 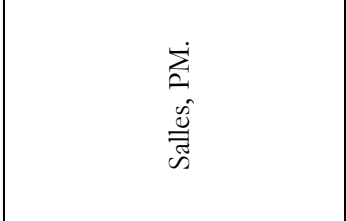 & 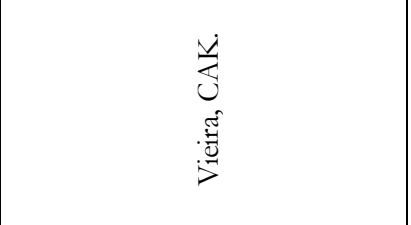 & 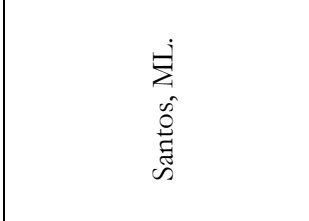 \\
\hline$\stackrel{m}{\sim}$ & \pm & $\stackrel{2}{n}$ & $\stackrel{\circ}{\sim}$ & 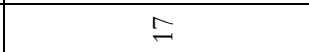 \\
\hline
\end{tabular}




\begin{tabular}{|c|c|c|c|}
\hline 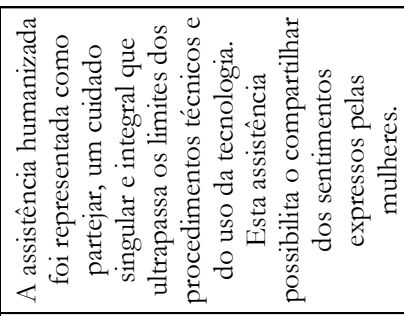 & 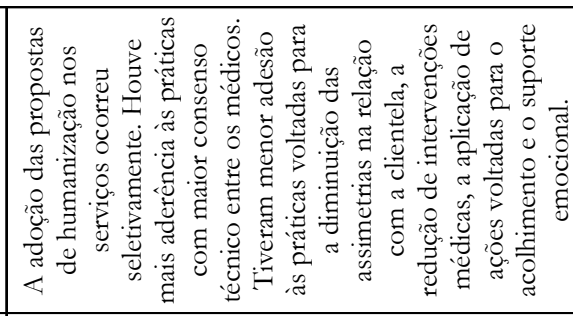 & 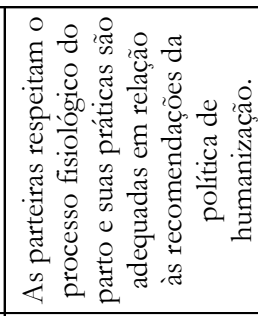 & 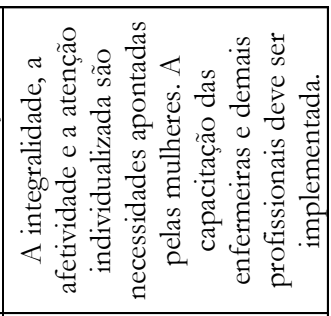 \\
\hline 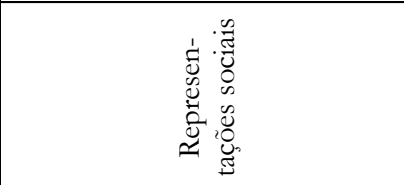 & & 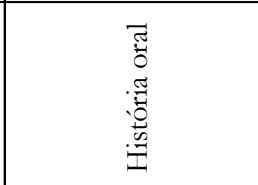 & \\
\hline 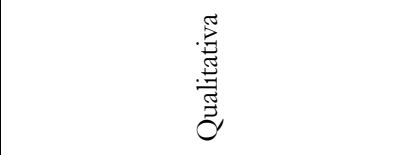 & 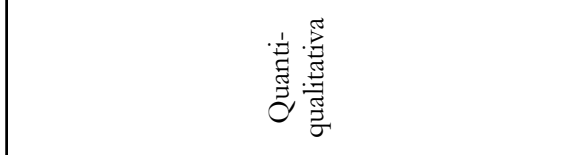 & 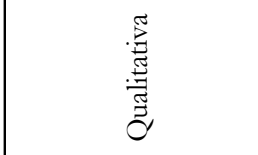 & 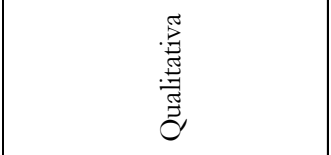 \\
\hline §̊ & ڤి & ڤి & ڤ్రి \\
\hline 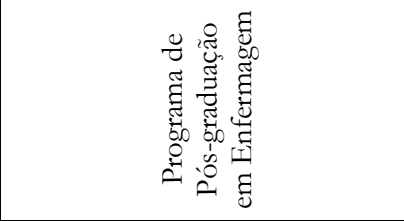 & 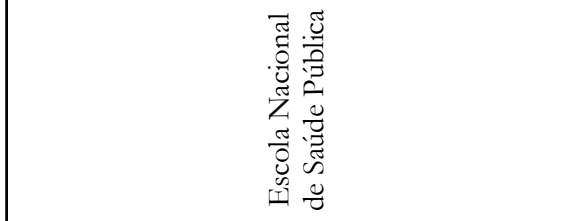 & 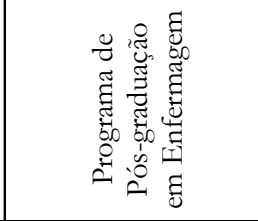 & 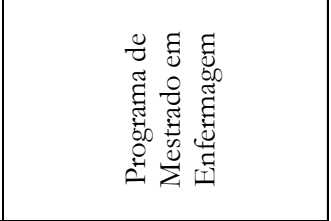 \\
\hline 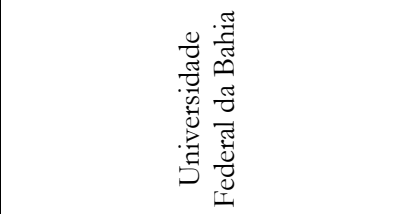 & 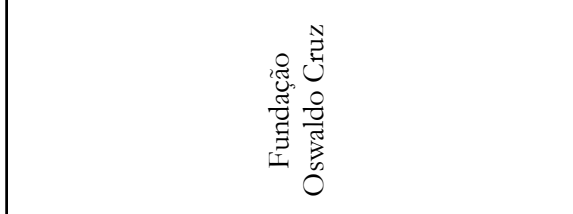 & 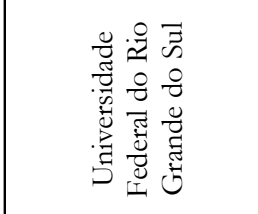 & 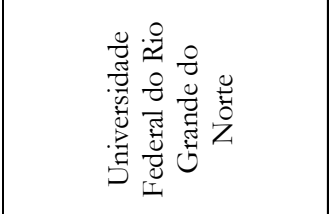 \\
\hline 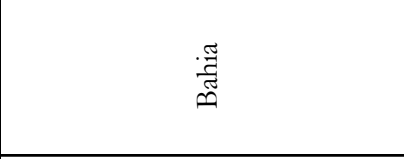 & 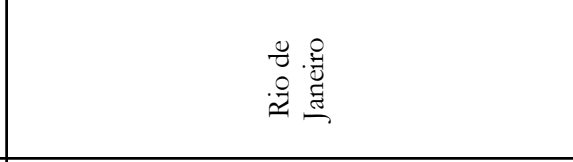 & 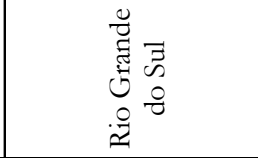 & 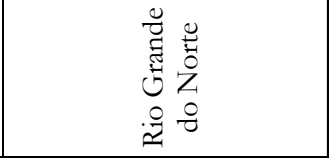 \\
\hline 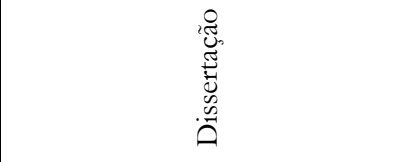 & 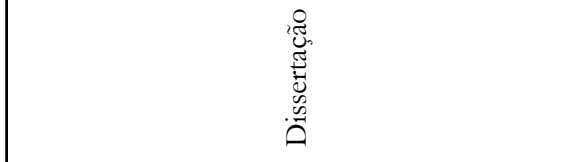 & 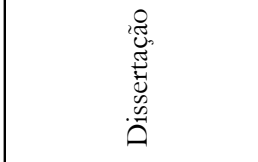 & 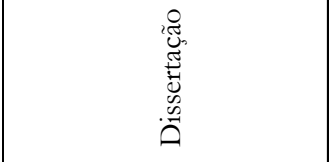 \\
\hline 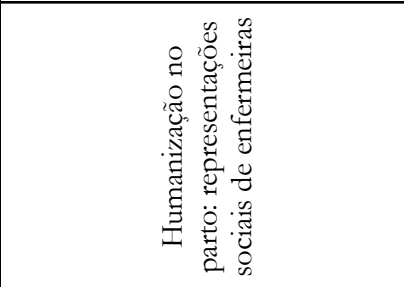 & 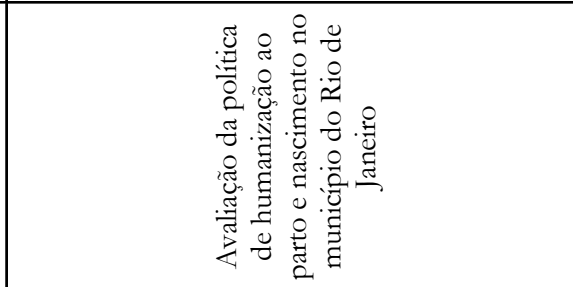 & 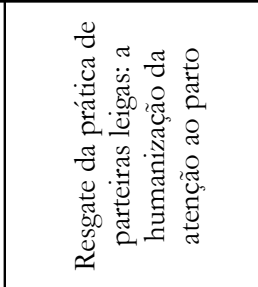 & 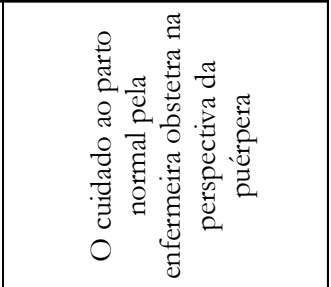 \\
\hline 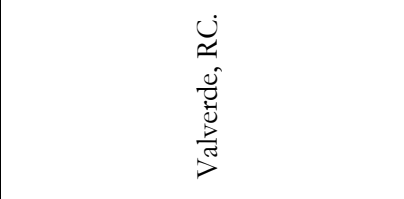 & 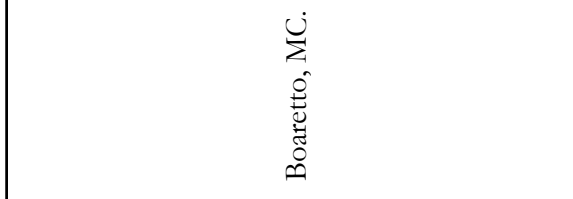 & 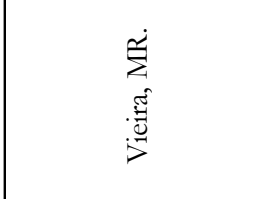 & 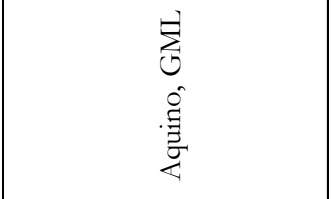 \\
\hline$\stackrel{\infty}{\sim}$ & 9 & ণ & $\vec{\sim}$ \\
\hline
\end{tabular}




\begin{tabular}{|c|c|c|c|c|}
\hline 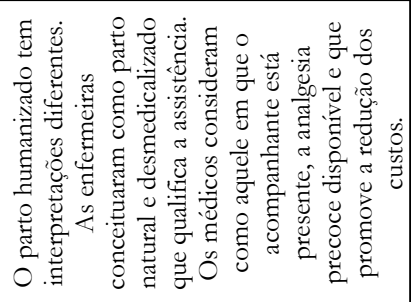 & 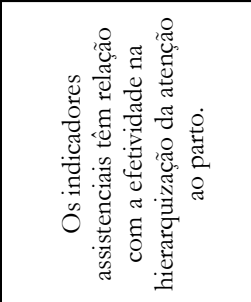 & 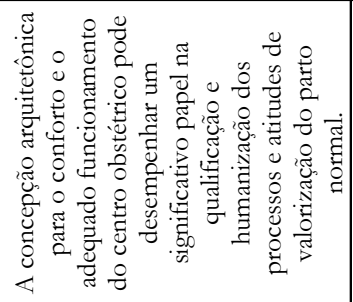 & 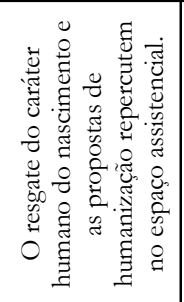 & 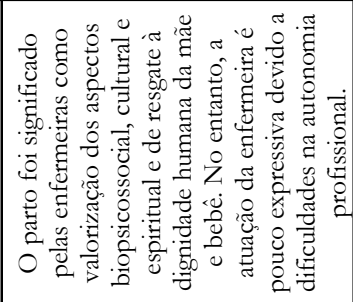 \\
\hline & 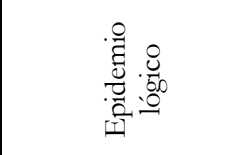 & & 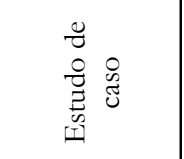 & 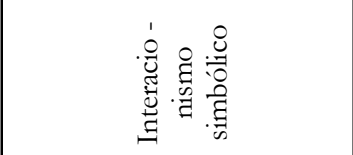 \\
\hline 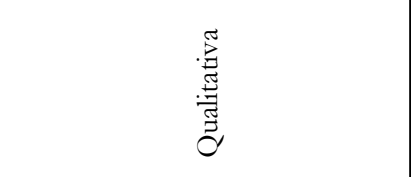 & 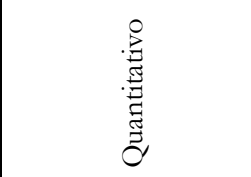 & 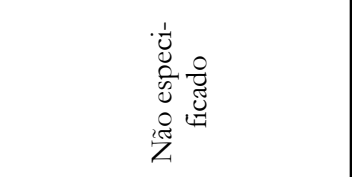 & 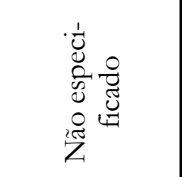 & : \\
\hline$\hat{\tilde{\Omega}}$ & $\hat{\tilde{\Omega}}$ & $\hat{\tilde{\sigma}}$ & $\hat{\tilde{\Omega}}$ & $\hat{\tilde{\Omega}}$ \\
\hline 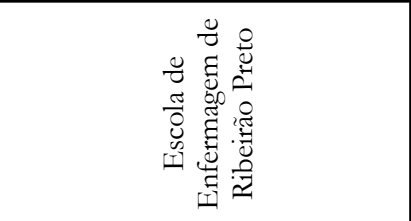 & 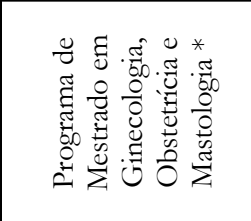 & 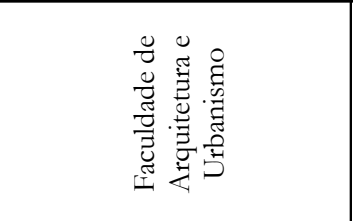 & 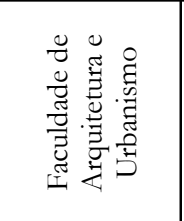 & 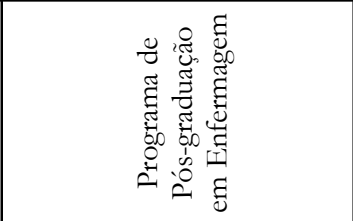 \\
\hline 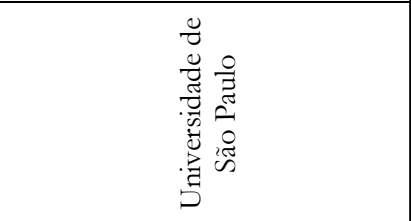 & 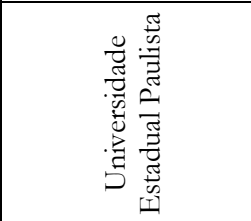 & 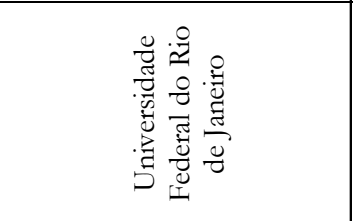 & 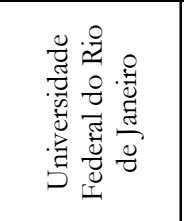 & 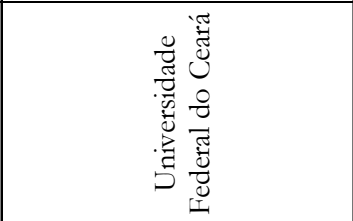 \\
\hline 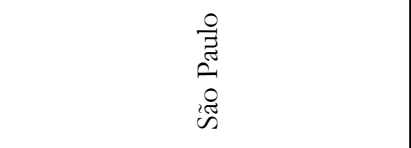 & 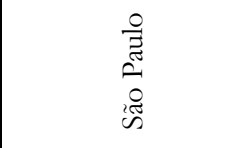 & 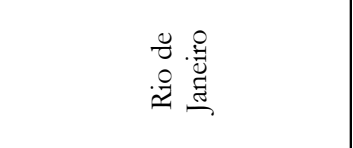 & 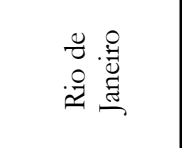 & Uूँ \\
\hline 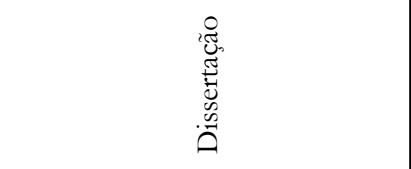 & 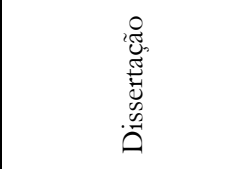 & 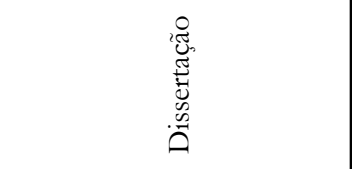 & 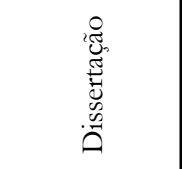 & 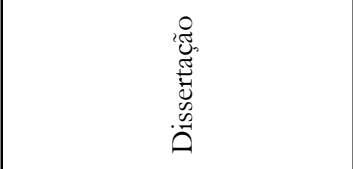 \\
\hline 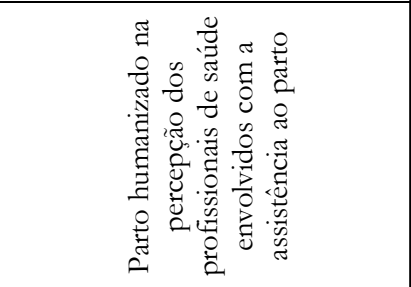 & 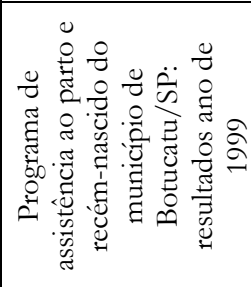 & 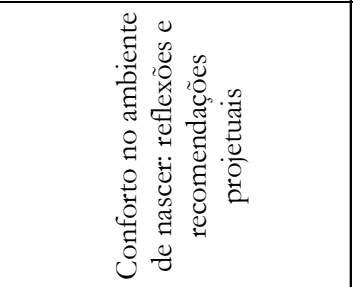 & 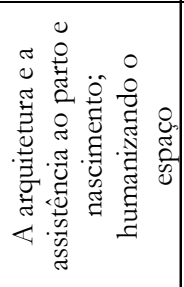 & 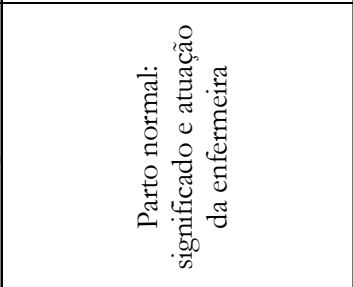 \\
\hline 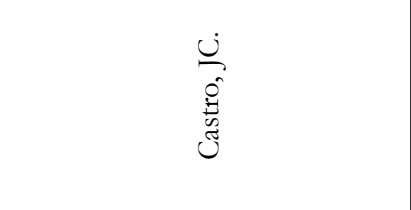 & $\begin{array}{l}\dot{u} \\
\dot{0} \\
0 \\
0 \\
\dot{0} \\
\dot{j}\end{array}$ & 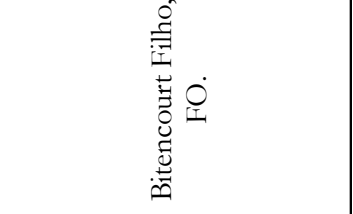 & $\begin{array}{l}\dot{0} \\
\dot{\Xi} \\
\bar{\Xi} \\
\dot{0}\end{array}$ & 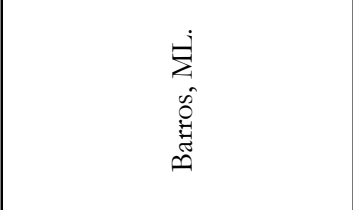 \\
\hline ป & $\tilde{\imath}$ & $\stackrel{J}{d}$ & $\stackrel{\leftrightarrow n}{\sim}$ & ㄱ \\
\hline
\end{tabular}




\begin{tabular}{|c|c|c|c|}
\hline 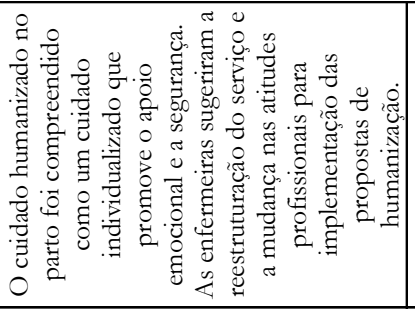 & 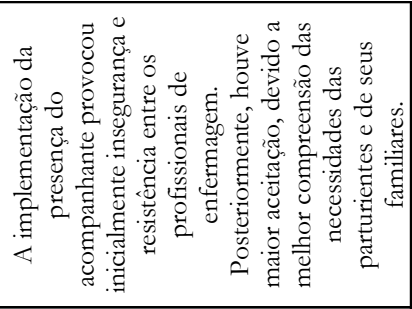 & 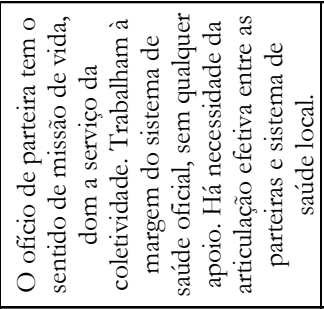 & 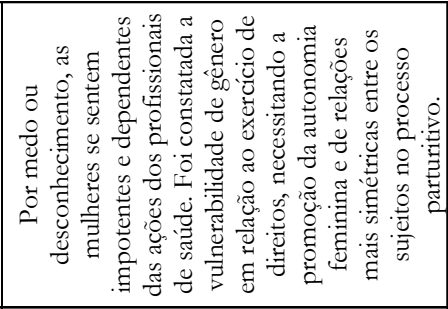 \\
\hline & 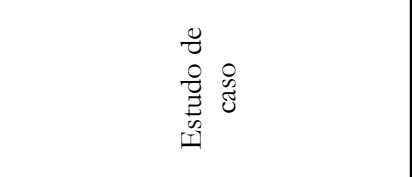 & 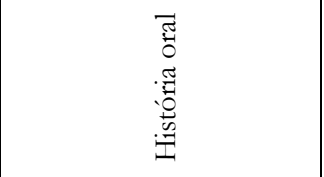 & \\
\hline 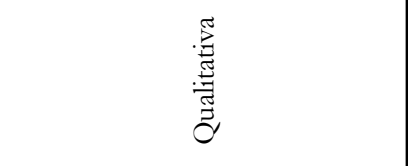 & 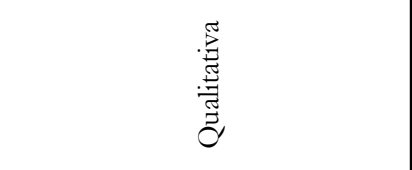 & 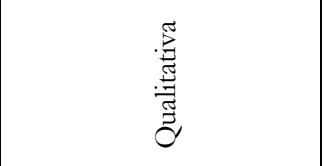 & 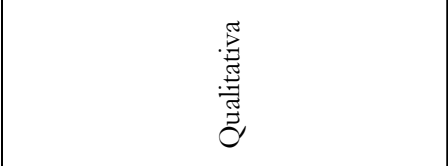 \\
\hline ڤి & ڤ్ & 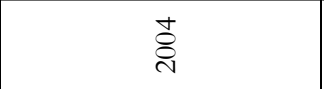 & 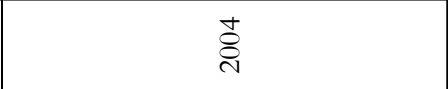 \\
\hline 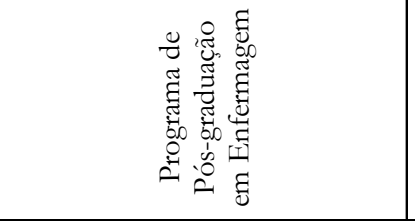 & 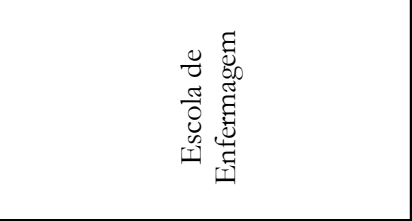 & 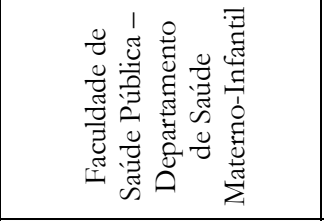 & 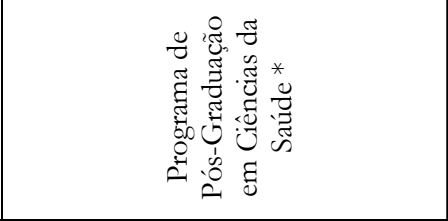 \\
\hline 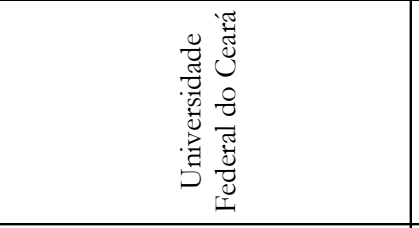 & 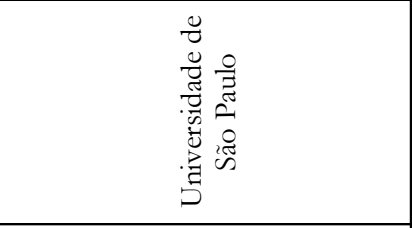 & 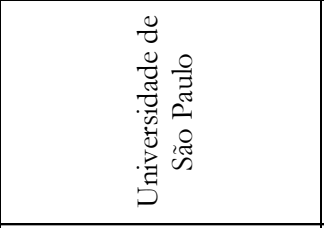 & 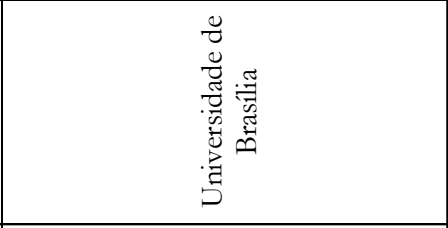 \\
\hline נूّ & 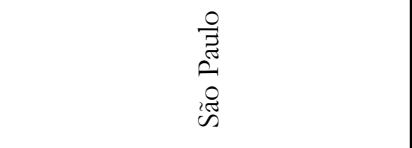 & 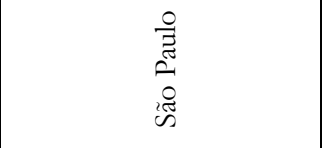 & 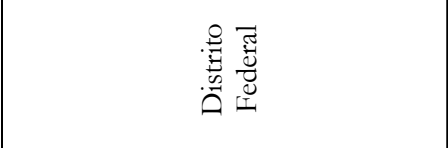 \\
\hline 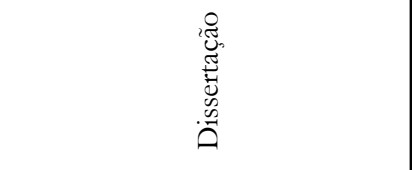 & 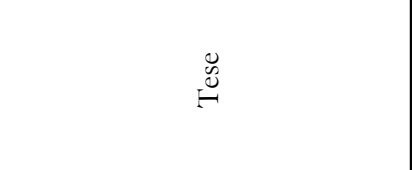 & 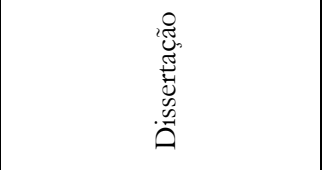 & 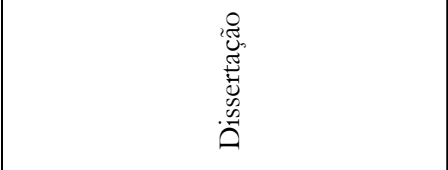 \\
\hline 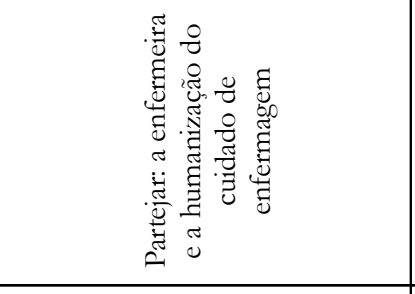 & 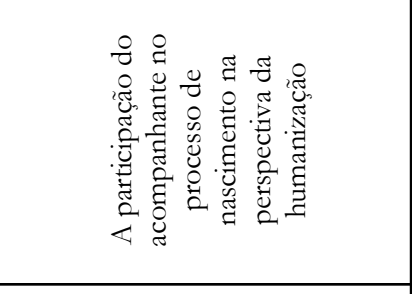 & 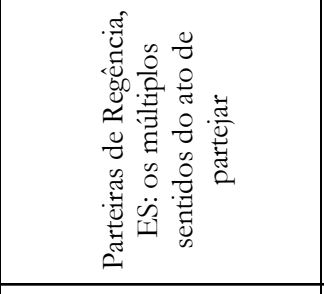 & 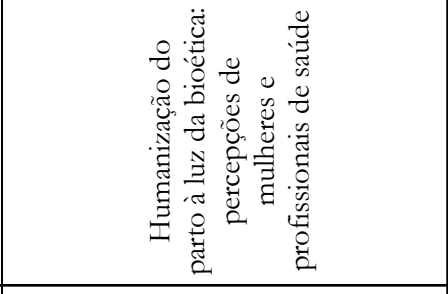 \\
\hline 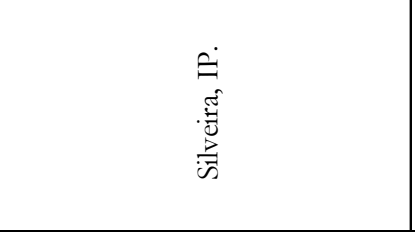 & 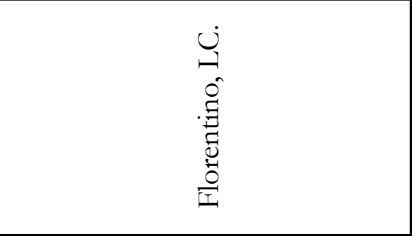 & 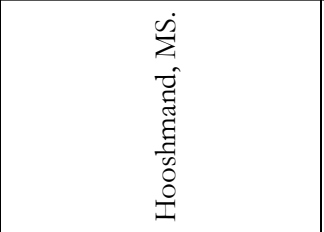 & 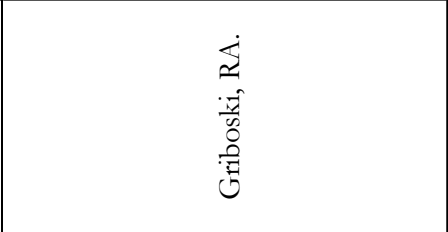 \\
\hline$\hat{\lambda}$ & $\stackrel{\infty}{\sim}$ & $\stackrel{\mathrm{\lambda}}{ }$ & $\stackrel{i}{i}$ \\
\hline
\end{tabular}

